* Doutora em Direito Político e Econômico pela Universidade Presbiteriana Mackenzie (MACKENZIE). Doutora em Integração da América Latina pela Universidade de São Paulo (USP). Mestre em Direito pela Pontifícia Universidade Católica de São Paulo (PUC/ SP). Especialista em Direito do Trabalho pela Universidade Braz Cubas (UBC). Especialista em Economia Empresarial pela Universidade Estadual de Londrina (UEL). Bacharel em Direito pela Universidade Estadual de Londrina (UEL). Graduada em Ciências Econômicas pela Universidade Estadual Paulista Júlio de Mesquita Filho (UNESP). Email:julianecaravieri@gmail. com

**Mestrando em Direito Público pela Universidade Federal de Uberlândia (UFU). Especialista em Direito Processual Civil pela Universidade Candido Mendes (UCAM). Especialista em Direito Constitucional pela Damásio Educacional (DAMASIO). Bacharel em Direito pela Universidade de Patos de Minas (UNIPAM). Email: igorlimaafonso@gmail. com

\section{O DIREITO E ACESSO À JUSTIÇA EFETIVA E EM TEMPO RAZOÁVEL E O PACTO DE SAN JOSÉ DA COSTA RICA NA PROTEÇÃO DO DIREITO À SAÚDE}

THE RIGHT TO EFFECTIVE AND REASONABLE JUSTICE AND THE PACT OF SAN JOSÉ OF COSTA RICA IN REGARDS TO THE PROTECTION OF HEALTH

\section{Juliane Caravieri Martins* Igor Vinícius de Lima Afonso**}

Como citar MARTINS, Juliane Caravieri; AFONSO, Igor Vinícius de Lima. O direito e acesso à justiça efetiva e em tempo razoável e o pacto e san-josé da costa rica na proteção do direito à saúde. Scientia Iuris, Londrina, v. 24, n. 2, p.81-100, jul. 2020. DOI: $10.5433 / 2178-8189.2020 v 24 n 2 p 81$. ISSN: $2178-8189$.

Resumo: Esta pesquisa analisou o direito de acesso à justiça tutela jurisdicional justa, efetiva e em tempo razoável - sob a ótica da Convenção Americana de Direitos Humanos, conhecida como Pacto de San José da Costa Rica, e das normas constitucionais brasileiras, verificando o seu impacto na proteção do direito à saúde no intuito de concretizar a justiça social. Questionou-se se este Pacto contribuiu para a concretização da tutela jurisdicional mais efetiva e em tempo razoável do direito à saúde dos cidadãos brasileiros. Como resultados, observou-se que o referido tratado internacional contribuiu para a promoção do direito à saúde no Brasil ao permitir ao cidadão, mediante o fenômeno da judicialização de políticas públicas, o acesso à tutela jurisdicional mais justa e efetiva.

Palavras Chave: Convenção Americana de Direitos Humanos. Garantias judiciais. Acesso à justiça. Saúde.

Abstract: This research examines the right of access to justice fair, effective and timely judicial protection - from the perspective of the American Convention on Human Rights, also known as the Pact of San José of Costa Rica, and Brazilian constitutional norms, verifying wether they protected the right to health in order to realize social justice. Furthermore, this study questiones whether this Pact contributed to the protection of the right to health for Brazilians. In other words, this paper investigates if this international treaty contributed to the promotion of the right 
to health in Brazil by allowing citizens, through the phenomenon of judicialization of public policies, access to fairer and more effective judicial protection.

Keywords: American Convention on Human Rights. Judicial guarantees. Access to justice. Health. 


\section{INTRODUÇÃO}

É parte da cura o desejo de ser curado

Lúcio Aneu Sêneca

(4 a.C. - 65 d.C.)

Desde tempos remotos da vida em sociedade, a concepção de justiça se apresenta como aspiração do ser humano, principalmente na contemporaneidade em que ganharam evidência a necessidade de sua concretização sob um viés distributivo e, indo mais além, social. A Constituição brasileira de 1988 destacou, no seu Preâmbulo, a justiça como um dos valores supremos de uma sociedade fraterna, pluralista e sem preconceitos, fundada no comprometimento com a solução pacífica dos conflitos, salvaguardando o exercício dos direitos fundamentais individuais e coletivos. Para garantir um convívio social equilibrado numa sociedade de massas, é necessário que o Poder Judiciário esteja comprometido com valores ético-jurídicos, de maneira que os cidadãos tenham acesso à tutela jurisdicional justa, efetiva e em tempo razoável.

Além disso, como integrante do plexo de garantias fundamentais no Estado Democrático de Direito (art. $1^{\circ}$, caput, CF), a Convenção Americana de Direitos Humanos (1969) - Pacto de San José da Costa - foi ratificada pelo Brasil, integrando a ordem jurídica pátria na condição de norma materialmente constitucional, tendo aplicação imediata (art. $5^{\circ}, \S \S 2^{\circ}$ e $3^{\circ}, \mathrm{CF}$ ). Tal Pacto dispõe sobre garantias judiciais (art. $8^{\circ}, \S 1^{\circ}$ ), em especial o acesso à justiça, prevendo, ainda, a proteção judicial (art. 25) ao permitir a impetração de recursos pelos cidadãos em atendimento ao duplo grau de jurisdição e a duração razoável do processo.

Nesse contexto, o Poder Judiciário estatal deverá promover, de forma menos gravosa aos cidadãos, a resolução dos conflitos sociais mediante a prestação de uma tutela jurisdicional justa, efetiva e em tempo razoável no intuito de concretizar a justiça social, sobretudo ante o basilar e indispensável direito à saúde. Portanto, a fim de fortalecer o Estado Democrático e Social de Direito no Brasil, é imperiosa a análise da Convenção Americana de Direitos Humanos e seu impacto na ordem jurídica pátria, visando à efetivação das normas constitucionais com fulcro, no presente estudo, do direito à saúde.

Então, o problema desta pesquisa será averiguar se a Convenção Americana de Direitos Humanos contribuiu, nestes cinquenta anos de sua vigência no subsistema regional de proteção aos direitos humanos, para a tutela jurisdicional justa, efetiva e em tempo razoável do direito à saúde garantido na Carta Constitucional brasileira (arts. $6^{\circ}$ e 196, CF), sobretudo ante as garantias e proteções judiciais previstas neste tratado internacional que foram incorporadas no sistema jurídico nacional. Como metodologia científica, a pesquisa utilizou os métodos dialético e histórico-sociológico. Quanto à técnica de pesquisa, utilizou-se a bibliográfico-exploratória.

Do ponto de vista formal e didático, o presente estudo foi dividido em quatro partes: primeiramente, buscou-se compreender a concepção de justiça, analisando criticamente as justiças distributiva e social; posteriormente, analisou-se a Convenção Americana de Direitos Humanos - Pacto de San José da Costa Rica e o direito de acesso à justiça efetiva e em tempo razoável nele 
previsto; no terceiro tópico, apreendeu-se o direito de acesso à justiça efetiva e em tempo razoável na ordem constitucional brasileira e, por fim, adentrou-se na tutela jurisdicional justa, efetiva e em tempo razoável para a garantia do direito à saúde dos cidadãos brasileiros, tendo como diretriz os preceitos contidos no Pacto de San José da Costa Rica.

Logo, esta pesquisa objetivou contribuir para as discussões atualíssimas sobre o Cinquentenário do Pacto de San José da Costa Rica e sua contribuição para a concretização no Brasil da prestação de uma tutela jurisdicional justa, efetiva e em tempo razoável para a proteção do direito à saúde com vistas ao atingimento mais pleno da justiça social.

\section{DA JUSTIÇA DISTRIBUTIVA À JUSTIÇA SOCIAL - ALGUMAS REFLEXÕES}

$\mathrm{Na}$ contemporaneidade, os seres humanos estão envoltos em relações sociais, políticas e econômicas cada vez mais complexas que necessitam de expressiva regulação pelo direito a fim de se buscar a solução pacífica para os conflitos e a convivência mais harmônica na sociedade pautada em valores éticos mínimos e essenciais. Nesse contexto, a ideia de justiça se apresenta como valor fundamental para o sistema jurídico porque "a justiça é ideia específica do direito. Está refletida em maior ou menor grau de clareza ou distorção em todas as leis positivas e é a medida de sua correção" (ROSS, 2008, p. 313).

Como a sociedade e o próprio Direito estão em constante transformação desde seus primórdios, aprimorando o "justo" e o "adequado", a concepção de justiça também esteve em reconstrução ao longo dos séculos. No Praecepta Juris, Ulpiano (150-223) entendeu a justiça como "a vontade firme e constante de dar a cada um o seu direito" (iustia est constans et perpetua voluntas ius suum cuique tribuendi) a qual se concretizaria mediante a realização de deveres impostos aos seres humanos pelo próprio direito, a saber: "viver honestamente", "não lesar o outro", "dar a cada um o que é seu" (honeste vivere, alterum non laedere, suum cuique tribuere) (MARKY, 2010).

"Viver honestamente" dependerá do conceito que se tem a priori de honestidade numa determinada sociedade ou situação fática. "Não lesar o outro" dependerá de uma definição mais precisa da extensão e do conteúdo da lesão e quais bens foram afetados. Finalmente, "dar a cada um o que é seu" estará atrelado ao patrimônio material ou imaterial pertencente a cada indivíduo, segundo suas condições e características pessoais. Tais preceitos apontavam as dificuldades em se delimitar o significado, o conteúdo e o alcance da ideia de justiça (MARKY, 2010).

Aristóteles já identificava a justiça como completa virtude e excelência, pois "cada homem julga bem as coisas que conhece, e desses assuntos ele é bom juiz. Assim, o homem instruído a respeito de um assunto é bom juiz nesse assunto, e o homem que recebeu instrução a respeito de todas as coisas é bom juiz em geral” (ARISTÓTELES, 2006, p. 19). No exercício do ato de julgar, as ações devem objetivar o bem supremo dos cidadãos da pólis, pois, para o pensamento aristotélico, a justiça era a completa virtude advinda do hábito. Para o exercício desta virtude, seria necessário conhecer, julgar, ponderar, discernir, calcular e deliberar. 
Segundo a opinião geral, a justiça é aquela disposição de caráter que torna as pessoas propensas a fazer o que é justo, que as faz agir justamente e a desejar o que é justo; e de modo análogo, a injustiça é a disposição que leva as pessoas a agir injustamente e a desejar o que é injusto. [...] Com efeito, a justiça é a virtude completa no mais próprio e pleno sentido do termo, porque é o exercício atual da virtude completa (ARISTÓTELES, 2006, p. 103-105).

Assim, a virtude aparece como elemento intrínseco do ser humano que, naturalmente, buscaria o bem. Como a virtude é uma faculdade prática, construída pelo hábito, necessariamente implica numa ação, num agir humano, numa disposição de caráter em busca de uma mediania. Então, é através dessa ação que se concretiza a virtude humana de fazer o bem e o justo em relação ao seu semelhante. Logo, a justiça seria a virtude mais completa, pois “[...] somente a justiça, entre todas as virtudes, é o 'bem de um outro', pois, de fato, ela se relaciona com o próximo, fazendo o que é vantajoso a um outro, quer se trate de um governante, ou de um membro da comunidade" (ARISTÓTELES, 2006, p. 105).

Portanto, Aristóteles entende que a justiça é a disposição de caráter que torna as pessoas propensas a fazer o que é justo, agir justamente e desejar o justo, pois o homem sem lei é injusto e o cumpridor da lei é justo, logo, ele aponta a existência de, basicamente, duas espécies de justiça: a distributiva e a corretiva ou reparadora.

A justiça distributiva pressuporia uma distribuição de honras, bens ou de qualquer outra coisa divisível entre os membros da sociedade segundo uma igualdade proporcional. Assim, na distribuição de vantagens e encargos se consideraria a situação particular e o mérito de cada um, em respeito ao princípio jurídico da isonomia. Portanto, o justo seria proporcional e o injusto violaria a proporção. Logo, segundo Aristóteles (2006, p. 111), no caso do injusto "[...] um dos termos se torna grande demais e o outro muito pequeno, como efetivamente acontece na prática, pois o homem que age injustamente fica com uma parte muito grande daquilo que é bom, e o que é injustamente tratado fica com uma parte muito pequena".

Por sua vez, a justiça corretiva, reparadora ou comutativa estaria presente nas transações voluntárias e involuntárias, apresentando caráter reparador, pois seria a virtude da proporcionalidade entre as coisas de sujeitos pressupostamente iguais entre si. Esta forma de justiça estaria mais relacionada aos casos em que uma pessoa pediria reparação ao receber uma ofensa de outra pessoa. Tal justiça se destinaria aos objetos, pois seria "[...] o meio-termo entre perda e ganho" (ARISTÓTELES, 2006, p. 110).

A partir de tais preceitos aristotélicos, a ideia de justiça distributiva ganhou evidencia na contemporaneidade porque pressuporia a distribuição de benefícios entre os membros de uma sociedade ou da comunidade internacional segundo o mérito e as necessidades de cada um (povos, nações, Estados etc.), pautando-se em normas de cooperação e solidariedade.

Então, à luz do processo de "reconstrução" dos direitos humanos em nível internacional e nacional após meados do século XX com o término da Segunda Guerra Mundial, o direito se pautou 
mais na busca pela efetivação da justiça distributiva, pois atenderia a "[...] melhor distribuição possível dos bens, dos direitos e dos deveres entre os homens" (BERGEL, 2006, p. 26). Não se pode olvidar que onde está a sociedade, estará o direito e não há nenhuma atividade social desprovida de regulamentação jurídica (ubi societas, ibi jus; ibi jus ibi societas), pois "é certo que o direito se apodera do homem desde antes de seu nascimento e o mantém sob sua proteção até depois de sua morte" (RÁO, 2005, p. 51).

Entretanto, com o aprofundamento das desigualdades socioeconômicas a partir do capitalismo industrial, a concepção de justiça distributiva se mostrou insuficiente para atender aos anseios sociais pelo direito e, na atualidade, deve-se ir mais além buscando a efetivação da ideia de justiça social sobretudo numa sociedade inserta na globalização econômica, neoliberal e excludente que aprofunda as desigualdades sociais e regionais no Brasil e no mundo.

A concepção de justiça social constou das Encíclicas integrantes da Doutrina Social da Igreja, sendo utilizou pelo Papa Pio XI com certa frequência na Quadragesimo Anno (15 de maio de 1931) que estabeleceu o princípio diretivo da justa distribuição, assim entendido:

É necessário que as riquezas, em contínuo incremento com o progresso da economia social, sejam repartidas pelos indivíduos ou pelas classes particulares de tal maneira, que se salve sempre a utilidade comum, de que falava Leão XIII, ou, por outras palavras, que em nada se prejudique o bem geral de toda a sociedade. Esta lei de justiça social proíbe que uma classe seja pela outra excluída da participação dos lucros. [...] Cada um deve, pois, ter a sua parte nos bens materiais; e deve procurar-se que a sua repartição seja pautada pelas normas do bem comum e da justiça social. [...] (LESSA, 2004, p. 335).

Esta concepção de justiça social foi incorporada pela Organização Internacional do Trabalho (OIT) em seus instrumentos normativos, destacando-se no Preâmbulo da sua Constituição que "[...] a paz universal e duradoura deve se assentar sobre a justiça social” (USP, 2019). A Carta da Organização dos Estados Americanos (OEA, 2019) estabeleceu, ainda, em seu Preâmbulo que "[...] o verdadeiro sentido da solidariedade americana e da boa vizinhança não pode ser outro senão o de consolidar neste Continente [...] um regime de liberdade individual e de justiça social, fundado no respeito dos direitos essenciais do Homem" (USP, 2019).

Então, em nível internacional, a justiça social passou da condição de princípio diretivo de cunho ético para preceito jurídico integrado às declarações e tratados internacionais, sendo também foi incorporado na Constituição brasileira de 1988 que, dentre os objetivos fundamentais (art. $3^{\circ}$, $\mathrm{CF}$ ), evidenciou a construção de uma sociedade justa e solidária (I), com a erradicação da pobreza e da marginalização, bem como a redução das desigualdades sociais e regionais (III) mediante a promoção do bem de todos, sem preconceitos de origem, raça, sexo, cor, idade e quaisquer outras formas de discriminação (IV), "juridicizando" o preceito da justiça social que "[...] se deslocou do simples, embora instigante, conceito ideário, para o conceito maior de princípio, isto é, comando jurídico investigador do ordenamento do Direito e das relações sociais" (DELGADO, 2004, p. 37 , grifo do autor). 
Portanto, nos Estados Democráticos de Direito, incluindo o Brasil, é atributo do Poder Judiciário estatal a resolução pacífica dos conflitos sociais, buscando a efetividade dos direitos dos cidadãos através da prestação de uma tutela jurisdicional justa e efetiva, sendo almejada a aplicação da justiça social a fim de proteger os direitos humanos e fundamentais, principalmente no caso do direito à saúde ora analisado.

\section{O PACTO DE SAN JOSÉ DA COSTA RICA E O DIREITO DE ACESSO À JUSTIÇA EFETIVA E EM TEMPO RAZOÁVEL}

No século XX eclodiram duas Grandes Guerras Mundiais: a Primeira durou de 1914 a 1918 e a Segunda, de 1939 a 1945, resultantes das hostilidades entre os Estados no plano internacional e motivadas por interesses econômicos e políticos. Entretanto, assistiu-se na Segunda Grande Guerra a prática de atrocidades contra a pessoa humana oriunda dos regimes totalitários, principalmente nazista e fascista.

Em função desse quadro internacional crítico, iniciaram-se conversações na conferência de Aliados, celebrada em Moscou, em 1943, acerca da constituição das Nações Unidas, pois

[...] as ideias germinais da ONU encontram-se na mensagem sobre o estado da União, dirigida pelo Presidente Franklin D. Roosevelt ao Congresso norteamericano em 6 de janeiro de 1941, bem como a chamada 'Carta do Atlântico', assinada pelo Presidente Roosevelt e o Primeiro-Ministro britânico Winston Churchill, em 14 de agosto do mesmo ano (COMPARATO, 2007, p. 215).

Assim, em 26 de junho de 1945, a Carta das Nações Unidas foi assinada pelos Estados signatários, incluindo o Brasil, após o término da Conferência de São Francisco, entrando em vigor em 24 de outubro do mesmo ano, constituindo, formalmente, a Organização das Nações Unidas (ONU). A assinatura da Carta da ONU e a Declaração Universal dos Direitos Humanos (1948) deram início ao sistema global de proteção aos direitos humanos que, posteriormente, foi ampliado com a assinatura e a ratificação por diversos países de vários outros tratados. Este sistema global deve ser compreendido como um padrão mínimo aceitável de direitos humanos, podendo ser ampliado e aprofundado por outros subsistemas regionais de proteção que congregam grupos de países com características históricas e culturais comuns.

Atualmente, o sistema regional de proteção aos direitos humanos é integrado pelos subsistemas europeu, interamericano e africano, vigendo, concomitantemente, com o sistema global. Os sistemas regionais almejam a proteção dos direitos humanos no âmbito regional no qual incidem, in casu, na Europa (subsistema europeu), na América (subsistema interamericano) e na África (subsistema africano) que é o mais incipiente de todos em função da história de opressão econômica e política que os povos africanos sofreram e ainda sofrem. Há, assim, relação harmônica e não colidente entre os subsistemas regionais e o sistema global, pois todos estão direcionados para a proteção dos direitos humanos, sendo inspirados por valores ético-jurídicos, especialmente, 
a dignidade da pessoa humana.

A completude e o inter-relacionamento justificam a existência conjunta do sistema global e dos subsistemas regionais, contribuindo, em nível internacional, para a tutela jurídica do respeito à pessoa humana como ser único e insubstituível porque "o propósito da coexistência de distintos instrumentos jurídicos - garantindo os mesmos direitos - é, pois, ampliar e fortalecer a proteção dos direitos humanos" (PIOVESAN, 2006, p. 226). Assim, cada um dos subsistemas regionais possui estrutura normativa própria que os regulamenta no âmbito de sua atuação, destacando-se, neste estudo, o subsistema interamericano nas Américas que:

[...] existe paralelamente a mecanismos internos e internacionais. Desde a sua criação, o sistema tem tido central relevância no reconhecimento e na proteção de direitos em ao menos três áreas: no fortalecimento do Estado de Direito, na adequação de regras nacionais aos parâmetros de direitos humanos e na consolidação de novos direitos (IKAWA; KWEITEL; MATTAR, 2008, p. 1135).

Em 1948, os Estados americanos reunidos na IX Conferência Internacional Americana, ocorrida em Bogotá, criaram a Organização dos Estados Americanos (OEA) que, segundo o art. $1^{\circ}$ da Carta da OEA, seria um organismo regional vocacionado para "conseguir uma ordem de paz e de justiça, para promover sua solidariedade, intensificar sua colaboração e defender sua soberania, sua integridade territorial e sua independência" (USP, 2019). Dentre os seus princípios orientadores, a Carta da OEA estabeleceu no art. $3^{\circ}$ que a "justiça e a segurança sociais seriam bases de uma paz duradoura" (alínea "j”) e a "educação dos povos deveria orientar-se para a justiça, a liberdade e a paz" (alínea "n") (USP, 2019). No contexto do desenvolvimento integral, o art. 47 da referida carta estabeleceu que os Estados-membros dariam "primordial importância ao estímulo da educação, da ciência, da tecnologia e da cultura, orientadas no sentido do melhoramento integral da pessoa humana, tendo como fundamento a democracia, a justiça social e o progresso" (USP, 2019).

Em abril de 1948, foi aprovada a Declaração Americana dos Direitos e Deveres do Homem, pioneira no estabelecimento do rol de direitos humanos, pois antecedeu, em oito meses, a Declaração Universal dos Direitos Humanos aprovada em dezembro de 1948. A Declaração Americana avançou em relação aos documentos internacionais da época ao dispor, no art. $1^{\circ}$, que os "indivíduos são, ao mesmo tempo, detentores de direitos e deveres correlatos, disciplinando que todo ser humano tem direito à vida, à liberdade e à segurança de sua pessoa, na medida em que pessoa é todo ser humano" (USP, 2019).

Acerca do direito de acesso à justiça, esta declaração previu, em seu art. 18, que "toda pessoa pode recorrer aos tribunais para fazer respeitar os seus direitos, contando com processo simples e breve, mediante o qual a justiça a proteja contra atos de autoridade que violem, em seu prejuízo, qualquer dos direitos fundamentais consagrados constitucionalmente" (USP, 2019). No art. 24, a declaração consagra também o direito de toda pessoa apresentar "petições respeitosas a qualquer autoridade competente, quer por motivo de interesse geral, quer de interesse particular, assim como o de obter uma solução rápida" (USP, 2019). Tais diretrizes respaldam o direito de 
acesso à prestação jurisdicional justa efetiva com duração razoável.

Posteriormente, o subsistema regional interamericano foi aperfeiçoado pela Convenção Americana sobre Direitos Humanos, conhecida como Pacto de San José da Costa Rica ${ }^{1}$ que foi aprovada com status de lei ordinária. Porém, entende-se que se trata de norma materialmente constitucional ao tutelar direitos humanos para os povos das Américas, incluindo o Brasil. O fato de o quórum de aprovação não ter sido qualificado (aprovação em cada Casa do Congresso Nacional, em dois turnos, por três quintos dos votos dos respectivos membros), nos termos do $\S^{\circ}$ do art. $5^{\circ}$ da Constituição, não desnatura sua condição de norma materialmente constitucional ${ }^{2}$, devendo prevalecer em face da legislação infraconstitucional brasileira. Em seu art. $8^{\circ}$, o Pacto de San José da Costa Rica dispôs sobre as garantias judiciais, destacando-se o parágrafo $1^{\circ}$ para viabilizar o acesso à justiça com vistas à concretude, pelo Estado brasileiro, do direito à saúde dos seus cidadãos, protegendo também a vida e a liberdade como bens jurídicos:

Toda pessoa terá o direito de ser ouvida, com as devidas garantias e dentro de um prazo razoável, por um juiz ou Tribunal competente, independente e imparcial, estabelecido anteriormente por lei, na apuração de qualquer acusação penal formulada contra ela, ou na determinação de seus direitos e obrigações de caráter civil, trabalhista, fiscal ou de qualquer outra natureza (USP, 2019, grifo nosso).

Além disso, o art. 25 do Pacto, prevê a proteção judicial, em especial para permitir a impetração de recursos pelo cidadão em atendimento ao duplo grau de jurisdição e a duração razoável do processo, a saber:

1. Toda pessoa tem direito a um recurso simples e rápido ou a qualquer outro recurso efetivo, perante os juizes ou tribunais competentes, que a proteja contra atos que violem seus direitos fundamentais reconhecidos pela Constituição, pela lei ou pela presente Convenção, mesmo quando tal violação seja cometida por pessoas que estejam atuando no exercício de suas funções oficiais.

2. Os Estados Membros comprometem-se:

a) a assegurar que a autoridade competente prevista pelo sistema legal do Estado decida sobre os direitos de toda pessoa que interpuser tal recurso;

b) a desenvolver as possibilidades de recurso judicial;

c) a assegurar o cumprimento, pelas autoridades competentes, de toda decisão em que se tenha considerado procedente o recurso (USP, 2019, grifo nosso).

1 Essa convenção foi aprovada em 22 de novembro de 1969 e entrou em vigor no plano internacional em 18 de julho de 1978. O Brasil ratificou-a em 09 de julho de 1992 e, posteriormente, aprovou-a pelo Decreto Legislativo $\mathrm{n}^{\mathrm{o}} 27$, de 25 de setembro de 1992, sendo promulgada pelo Decreto $n^{\circ}$ 678, de 06 de novembro de 1992 (USP, 2019).

2 Segundo Piovesan (2006, p. 328-329), "por força do art. 5 , § 2º da Constituição Federal de 1988, todos os tratados de direitos humanos, independentemente do quorum de aprovação, são materialmente constitucionais, compondo o bloco de constitucionalidade. O quorum qualificado introduzido pelo $\S 3^{\circ}$ do mesmo artigo (fruto da Emenda Constitucional n. 45/2004), ao reforçar a natureza constitucional dos tratados de direitos humanos, vem a adicionar um lastro formalmente constitucional aos tratados ratificados, propiciando a 'constitucionalização formal' dos tratados de direitos humanos no âmbito jurídico interno. Nessa hipótese, os tratados de direitos humanos formalmente constitucionais são equiparados às emendas à Constituição, isto é, passam a integrar formalmente o Texto. Com o advento do $\S 3^{\circ}$ do art. $5^{\circ}$ surgem, assim, duas categorias de tratados internacionais de proteção aos direitos humanos: a) os materialmente constitucionais; b) os material e formalmente constitucionais. Frise-se: todos os tratados internacionais de direitos humanos são materialmente constitucionais, por força do $\S 2^{\circ}$ do art. $5^{\circ}$. Para além de serem materialmente constitucionais, poderão, a partir do $\S 3^{\circ}$ do mesmo dispositivo, acrescer a qualidade de formalmente constitucionais, equiparando-se às emendas à Constituição, no âmbito formal”. 
Portanto, o Pacto de San José da Costa Rica foi incorporado no ordenamento jurídico pátrio com natureza de norma materialmente constitucional, indicando ao Estado brasileiro que o acesso à justiça não se efetiva apenas com a distribuição da petição inicial no órgão judiciário competente, mas vai muito além desse ato. Então, somente a prestação da tutela jurisdicional justa, efetiva e em tempo razoável - na condição de direito humano e fundamental - poderá concretizar a justiça social tão premente na atualidade, pois “[...] justiça atrasada não é justiça, senão injustiça qualificada e manifesta. Porque a dilação ilegal nas mãos do julgador contraria o direito das partes, e, assim, as lesa no patrimônio, honra e liberdade" (BARBOSA, 1997, p. 675).

\section{O DIREITO DE ACESSO À JUSTIÇA EFETIVA E EM TEMPO RAZOÁVEL NA CONSTITUIÇÃO BRASILEIRA DE 1988}

A Constituição de 1988, conhecida como Constituição Cidadã, no seu Preâmbulo, destacou a justiça como um dos valores supremos da sociedade fraterna, pluralista e sem preconceitos, fundada no comprometimento com a solução pacífica dos conflitos, salvaguardando aos cidadãos brasileiros e aos residentes em território nacional o exercício dos direitos civis e políticos, bem como dos direitos sociais, econômicos e culturais (BRASIL, 1988).

$\mathrm{O}$ acesso à tutela jurisdicional justa, efetiva e em tempo razoável (art. $5^{\circ}, \mathrm{XXXV}$ e LXXIV, LXXVIII, CF) se apresenta como direito fundamental e garantia da cidadania (art. $1^{\circ}$, II da $\mathrm{CF}$ ) porque, "como princípio do direito, a justiça delimita e harmoniza os desejos, pretensões e interesses conflitantes na vida social da comunidade" (ROSS, 2008, p. 313). Por força da Emenda Constitucional $n^{\circ} 45 / 2004$, o princípio da duração razoável do processo, no âmbito judicial e administrativo (art. $5^{\circ}$, LXXVIII, CF), foi explicitamente incluído no rol dos direitos e garantias fundamentais no intuito de assegurar decisões judiciais mais efetivas e em tempo razoável norteando a atividade judicante (BRASIL, 1988).

Nesse sentido, Cunha (2008, p. 32-33) afirma que o sistema judicial não deve estar apenas formalmente à disposição dos cidadãos, mas deverá, pronta e integralmente, reestabelecer direitos violados ou ameaçados, pois “[...] acessar uma Justiça que não estabelece o direito material (ou o faz apenas parcialmente), significa, em termos práticos, o mesmo que não acessála [...]". Caso contrário, haverá o esvaziamento dos direitos dos cidadãos, inclusive do direito de acesso à justiça cuja natureza também é de direito fundamental.

O Estado atraiu para si a competência no julgamento das lides no intuito de concretizar o bem comum - entendido como "o conjunto das condições sociais que permitem e favorecem nos homens o desenvolvimento integral da personalidade" (LESSA, 2004, p. 760) - e a paz social na vida em sociedade em contraposição ao uso da violência e do exercício arbitrário das próprias razões. Nos Estados Democráticos de Direito é inerente ao Poder Judiciário estatal, no exercício da jurisdição, a resolução pacífica dos conflitos sociais, buscando a efetividade dos direitos e a 
aplicação das justiças distributiva e social.

Portanto, a jurisdição é atividade estatal que deve se destinar à solução dos conflitos de modo justo e equânime em prol do bem comum dos cidadãos, possuindo garantias e princípios consagrados na ordem constitucional, tais como: devido processo legal (art. 5 $5^{\circ}$ LIV, CF); contraditório e ampla defesa (art. 5 $, \mathrm{LV}, \mathrm{CF}$ ); vedação da prova ilícita (art. 5º LVI, CF); juiz natural e vedação aos tribunais de exceção (art. $5^{\circ}$, XXXVII e LIII, CF); motivação das decisões judiciais (art. 93, IX, CF), dentre outros, no intuito de fortalecer a efetivação da justiça social, mormente no âmbitos dos direitos econômicos, sociais e culturais.

Atualmente, no Brasil, o aparato judiciário funciona numa lógica própria em que despontam a burocracia e o formalismo excessivo na análise e julgamento dos processos em afronta a preceitos constitucionais e ao Pacto de San José da Costa Rica, havendo desigualdade na distribuição da justiça, pois se convive com um direito para os oprimidos e outro para as "elites" que mantém uma paz social artificial ao beneficiar poucos. Há órgãos do Poder Judiciário que estão distantes do cotidiano do homem comum e de seus anseios, não acompanhando os ditames impostos pela Constituição desde 1988 e pela Convenção Americana de Direitos Humanos há cinquenta anos.

Portanto, em face da crescente judicialização de direitos vivenciada no Brasil nas últimas décadas, é imperioso garantir a todos o acesso à tutela jurisdicional justa, efetiva e em tempo razoável, em especial na proteção à saúde.

\section{A TUTELA JURISDICIONAL JUSTA, EFETIVA E EM TEMPO RAZOÁVEL PARA A PROTEÇÃO DO DIREITO À SAÚDE NO BRASIL SOB A ÓTICA DO PACTO DE SAN JOSÉ DA COSTA RICA}

Piovesan (2015, p. 2) preleciona a respeito da notoriedade do impacto do sistema interamericano de direitos humanos na composição de um constitucionalismo regional transformador, principalmente no contexto latino-americano, implicando no fortalecimento do Estado de Direito. Neste sentido, a Convenção Americana de Direitos Humanos - Pacto de San José da Costa Rica - foi importante instrumento normativo para a proteção e a promoção de direitos em seus países signatários, destacando-se, no presente estudo, o Brasil.

No mesmo sentido, ela aponta a necessidade de proteção dos direitos à igualdade e à diferença nos sistemas regionais, dentre os quais o interamericano, tal como no sistema global, destacando que cada sistema regional possui aparato jurídico próprio como, no caso, a Convenção Americana de Direitos Humanos que prevê a Comissão Interamericana de Direitos Humanos e a Corte Interamericana para a proteção aos direitos nela elencados (PIOVESAN, 2015, p. 307-308). De acordo com Novaes (2004, p. 33), o Estado de Direito é aquele que se encontra juridicamente limitado pelos direitos fundamentais, bem como vinculado à sua defesa e proteção, ressaltando a utilização dos direitos fundamentais como trunfos em face das maiorias.

O Preâmbulo do Pacto de San José da Costa Rica explicitou a necessidade de 
reconhecimento dos direitos essenciais da pessoa humana e o fato de que os mesmos não são apenas direitos dos nacionais de determinado Estado, mas haveria a proteção internacional (USP, 2019), amplamente reconhecida na modernidade, uma vez que os direitos humanos na ótica global estão no cerne dos discursos e análises jurídicas contemporâneos.

$\mathrm{O}$ art. $4^{\mathrm{o}}, 1$ da Convenção Americana (USP, 2019) ressaltou a importância do direito à vida, devendo ser protegida pela lei e, em geral, desde o momento da concepção. De forma expressa, também é disciplinado o direito à integridade pessoal, compreendendo o respeito aos aspectos físicos, psíquicos e morais do indivíduo. Embora tais prescrições tenham repercutido de forma mais intensa na seara criminal, por meio da vedação à pena de morte, torturas, tratos cruéis, desumanos ou degradantes, não se nega que tais direitos devam também, similarmente, repercutir na promoção do direito social à saúde em toda a sua extensão e compreensão nos Estados Democráticos de Direito.

Fiorati (1995, p. 3) dispõe que a Convenção Americana não disciplina expressamente os direitos sociais, econômicos e culturais, mas recomenda aos Estados-Partes a progressiva realização de tais contidos na Carta da Organização dos Estados Americanos. No entanto, o art. 26 da Convenção (USP, 2019) aponta a necessidade do desenvolvimento progressivo para a promoção de direitos econômicos, sociais e culturais, razão pela qual os Estados signatários se comprometeram a adotar as providências necessárias para sua efetivação, tanto no âmbito interno, como mediante cooperação internacional, especialmente em termos econômicos e técnicos a fim de progressivamente atingir plena efetividade a tais direitos.

Segundo Steinmetz (2004, p. 276), os direitos sociais são aqueles que exigem uma ação positiva do sujeito destinatário (Estado), constituindo direitos onerosos, pois exigiriam a disponibilidade de recursos financeiros e outros meios materiais para sua efetivação. Porém, não obstante a alardeada onerosidade, exige-se o seu cumprimento e tutela por parte do Estado (STEINMETZ, 2004, p. 282) ainda que em colaboração com a sociedade civil.

A Constituição brasileira de 1988 erigiu o direito à saúde à condição de direito social fundamental (art. $6^{\circ}$ ), incluindo a saúde, no art. 194, no sistema da seguridade social, além de fixar estrutura política complexa e abrangente para sua promoção (BARRETO JÚNIOR, PAVANI, 2013, p. 72). A fim de dar ressonância a vários princípios e regramentos constitucionais, a Lei ${ }^{\circ}$ 8.080/1990 - chamada de Lei Orgânica da Saúde - estabeleceu que a saúde é direito fundamental do ser humano, devendo o Estado prover as condições indispensáveis ao seu pleno exercício (art. $2^{\circ}$ ), por meio de assistência integral, com conjunto articulado de ações e serviços públicos que propiciem aos indivíduos e à coletividade atenção eficiente e adequada em todos os níveis de complexidade do sistema (BRASIL, 1990).

A partir de tal marco normativo, houve no Brasil nova sistemática de proteção à saúde com maior amplitude, competindo ao Estado sua prestação como, por exemplo, no caso de fornecimento gratuito de fármacos mediante políticas públicas. Entretanto, o direito à saúde deve possuir garantia mais ampla do aquela conferida aos demais direitos sociais em razão de estar diretamente relacionado à vida, bem jurídico basilar e elementar para concretização da dignidade 
da pessoa humana. Logo, o indivíduo sem o respeito ao seu direito básico a saúde não conseguirá gozar plenamente dos demais direitos humanos e fundamentais.

Nas lições de Cerqueira Júnior e Cavalcanti (2016, p. 6), o princípio da dignidade da pessoa humana, que está consagrado como direito fundamental na Constituição (art. $1^{\circ}$, III), é o princípio máximo do Estado Democrático de Direito e tem o condão de garantir que a vida e a saúde das pessoas sejam preservadas, já que não há como ter uma vida digna sem saúde. $\mathrm{O}$ direito à saúde deve ser reconhecido a todas as pessoas pelas nações e nos pactos internacionais ainda que implicitamente. Conforme entendimento de Suryan (2014, p. 6), a saúde não é apenas direito subjetivo de defesa contra agressões de terceiros, do Estado ou de outros Estados, mas também um direito prestacional em sentido estrito, estando correlacionado ao direito de ação para sua garantia e efetividade.

Os direitos humanos fundamentais, a exemplo do direito à saúde, devem ser garantidos pelo Estado, primeiro porque isso está explicitado na norma constitucional positivada, segundo porque a violação destes ocasiona a quebra do pacto social estabelecido e terceiro porque a possível insegurança gerada em virtude da quebra do pacto sinalizaria para a desordem social, evidenciando possível regressão do modelo atual de gestão, fato que nenhum Estado ou governo deve chancelar (CERQUEIRA JÚNIOR; CAVALCANTI, 2016, p. 8).

Tal situação também caracterizaria o descumprimento de tratados internacionais, implicando em sanções externas, inclusive econômicas, do país frente aos demais Estados, sendo a atual tendência. Uma das principais características do regime jurídico-constitucional do direito à saúde é sua conformação aos preceitos internacionais, inclusive estabelecidos pela Organização Mundial da Saúde que, no Informe Técnico n 571, dispôs que "la salud no es una mera ausencia de enfermedad, sino un estado óptimo de bienestar físico, mental y social. La salud no es algo que se posea como un bien, sino una forma de funcionar en armonía con su medio (trabajo, ocio, forma de vida en general)" (OMS, 1975, p. 9).

Logo, a saúde é compreendida como o estado de completo bem-estar físico, mental e social. Sarlet e Figueiredo (2011, p. 776) apontam que, além de considerações mais específicas acerca do regime jurídico-constitucional do direito à saúde, a sua concepção larga ante a consagração de outros direitos fundamentais sociais, tem sido objeto de proteção no direito internacional cujas normas dialogam com o sistema constitucional nacional, destacando-se diversos documentos protetivos, dentre os quais a Convenção Americana de Direitos Humanos que consagra em seus arts. $4^{\circ}$ e $5^{\circ}$ o direito à vida e à integridade física e pessoal.

Segundo Villey (2007), os direitos humanos são produto da era moderna, bem como em face da insuficiência de leis existentes em algumas partes do mundo, eles podem ser vistos como recursos e instrumentos do progresso do direito. Nessa senda, qualquer pacto internacional que verse sobre a sua promoção terá importante papel no avanço do Estado Democrático de Direito.

No que tange à promoção da saúde, principalmente em seu viés público, é importante se considerar que, além de direito fundamental, trata-se também de um dever fundamental, consoante previsão no art. 196 da Constituição de 1988. É, portanto, um direito-dever porque os 
deveres conexos e correlatos são reconhecidos na conformação constitucional do próprio direito fundamental, motivo pelo qual o direito à saúde impõe diferentes formas para sua efetivação (SARLET; FIGUEIREDO, 2011, p. 778).

As normas constitucionais, principalmente relacionadas à promoção da saúde, possuem aplicabilidade direta e imediata pelos magistrados e tribunais, pois os preceitos estabelecidos na Carta Magna dão sustentação para a sua judicialização, efetivando-os na vida dos cidadãos. $\mathrm{O}$ ativismo judicial na judicialização de políticas públicas impõe à Administração Pública que forneça gratuitamente medicamentos e tratamentos médicos/hospitalares, buscando-se efetivar a promessa constitucional de prestação universalizada dos serviços de saúde (CERQUEIRA JÚNIOR; CAVALCANTI, 2016, p. 8).

A judicialização de políticas públicas relacionadas à saúde já foi julgada em diversos momentos pelo Supremo Tribunal Federal (STF) que reconheceu a multifatoriedade envolvida nas ações judiciais que buscam a efetividade desse direito. Entretanto, foi no julgamento do Agravo Regimental da Suspensão de Tutela Antecipada (STA) $n^{\circ} 175$ que a Corte Constitucional estabeleceu parâmetros para a judicialização da saúde (BRASIL, 2019). A STA nº 175 foi o primeiro julgado expressivo sobre a temática do direito à saúde após a Audiência Pública n ${ }^{\circ}$ 04, sendo a relatoria do Ministro Gilmar Mendes cujo voto foi ratificado pelo Plenário do STF, fixando novos parâmetros a serem observados pelo Poder Judiciário brasileiro no deferimento das tutelas referentes ao direito à saúde, a saber:

1) É necessário, inicialmente, perquirir se há uma política pública estatal que abranja a prestação de saúde pleiteada pela parte. Nestas hipóteses, o judiciário deve intervir para seu cumprimento no caso de omissões ou prestação ineficiente.

2) Caso o primeiro ponto não esteja presente, em seguida, o juiz precisa verificar se a prestação de saúde pleiteada está contida nos protocolos do SUS, caso não esteja, é preciso distinguir se: 2.1) A não prestação decorre de uma omissão legislativa ou administrativa, de uma decisão administrativa de não fornecê-la, ou de uma vedação legal a sua dispensação. No caso de omissão administrativa, o registro na ANVISA é condição imprescindível para o fornecimento de medicamentos, impedindo sua importação (com exceção dos medicamentos adquiridos por intermédio de organismos multilaterais internacionais, desde que utilizados em programas em saúde pública do Ministério da Saúde). Na hipótese de decisão administrativa de não fornecer, o juiz deve analisar se o SUS fornece tratamento alternativo, que será privilegiado em detrimento de outros. Porém, poderá haver contestação judicial do ponto no caso de ineficácia do tratamento; 2.2) Os medicamentos e tratamentos são experimentais; caso o sejam, o Estado não está obrigado a fornecê-los; 2.3) Os tratamentos novos ainda não foram incluídos nos protocolos do SUS, mas são fornecidos pela rede particular de saúde. Nesses casos, os tratamentos podem ser deferidos, desde que seguidos de ampla instrução probatória e com reduzida possibilidade de deferimentos cautelares (MAGALHÃES; FERREIRA, 2019).

O estabelecimento de parâmetros para a judicialização da saúde por uma lado seria importante para os jurisdicionados e a sociedade em geral porque já indicaria os deveres do Estado 
na concretização desse direito social fundamental nos termos do art. 196, CF (BRASIL, 1988); mas, por outro prisma, poderia significar um engessamento dos magistrados de primeira instância na análise das particularidades de cada caso em concreto. Assim, tais parâmetros devem ser analisados com cautela e ressalvas, sobretudo em razão da multifatoriedade (jurídica, econômica, social etc.) existente nas ações apresentadas ao Poder Judiciária buscando a justiça social na efetividade do direito à saúde.

Nesse sentido, apesar de analisar os direitos fundamentais sob a perspectiva da Constituição portuguesa, Nabais (2007, p. 66) aponta que o tratamento constitucional dos direitos fundamentais repousa na contraposição entre os próprios direitos, liberdades e garantias individuais em face dos direitos econômicos sociais e culturais. A concretização do direito a saúde encontra barreiras em questões econômico-financeiras do Estado, embora seja inegável a necessidade de sua promoção e efetivação aos cidadãos. Os direitos sociais, inclusive o direito à saúde, possuem dimensão economicamente relevante em razão de serem direitos prestacionais, tendo por objeto a destinação, a distribuição e a redistribuição do bem da vida pleiteado pelo jurisdicionado.

De acordo com Alexy (2008, p. 202), quando há direito a prestações em face do Estado, tem-se, em regra, ações positivas fáticas que requerem uma execução propriamente dita as quais se fundamentariam num mínimo existencial a ser garantido aos particulares. Porém, o autor aponta, ainda, que tais direitos a prestações em face do Estado também poderão ser realizados mediante prestações normativas, voltadas aos atos estatais de criação de normas, tratando de importante forma de concretização desses direitos fundamentais.

No Brasil, a judicialização da saúde é realidade diuturna nos tribunais em razão do elevado número de ações judiciais requerendo a efetivação desse direito social, seja para fornecimentos de medicamento, tratamentos médicos e cirurgias de média a alta complexidade, de obtenção de leitos hospitalares para internação etc., buscando a prestação direta do direito à saúde em face do Estado e de seus entes federativos. Tal situação acarreta inúmeras demandas judiciais em face da Administração Pública que deverão cumprir de imediato cumprimento as decisões judiciais proferidas, normalmente em sede de liminares e tutelas de urgência, para a promoção material da saúde que não foi implementada pelas políticas públicas.

O número exacerbado de demandas judiciais indica que há omissão do Estado na implementação dos mais diversos tipos de políticas públicas de saúde, faltando atenção adequada à necessidade de se primar pela universalidade do atendimento público consoante preceitos constitucionais e da Lei no 8.080/1990 (BRASIL, 1990). Stark (2009, p. 291) afirma ser importante que a legislação estatal tenha êxito em conseguir, na situação social concreta, um equilíbrio entre as principais finalidades do Estado, podendo ocorrer um fracasso quando as prestações sociais puderem ser reclamadas desproporcionalmente. Desse modo, a questão da judicialização deve ser analisada com esmero e cautela a fim de que não surtam efeitos contrários à pretendida satisfação plena e imediata do direito à saúde.

O acesso ao Poder Judiciário ainda é um desafio nos Estados Democráticos de Direito, principalmente em países em desenvolvimento como o Brasil, pois é notório que o acesso à justiça 
ainda é privilégio de quem possui poder econômico e aquisitivo maior, pois as Defensorias públicas no país não conseguem atender todas as demandas da população carente. Assim, depreende-se que a judicialização da saúde não é ferramenta de promoção de direitos acessível a todos os cidadãos em igualdade de condições, atentando contra o regramento constitucional de igualdade e de universalidade da prestação de serviços públicos.

Rocha e Alves (2011, p. 134-135) apontam que não há duvidas de que o acesso à justiça é direito fundamental presente em diversos textos supralegais, bem como que se trata da própria garantia do Estado Democrático de Direito. Dado o caráter formal e substancial de direito humano e, ao mesmo tempo, de direito fundamental (ROCHA; ALVES, 2011, p. 135-136), o acesso à justiça não é exclusividade do direito pátrio, estando presente na maioria dos ordenamentos jurídicos dos países de democracia moderna e diversos tratados internacionais.

Neste contexto, o Pacto de San José da Costa Rica também é importante instrumento do sistema interamericano de direitos humanos para a viabilização do acesso à justiça, influenciando o Constitucionalismo dos países da América ao prever garantias e proteções judiciais, art. $8^{\circ}$ e art. 25 respectivamente, permitindo a impetração de recursos pelo cidadão em atendimento ao duplo grau de jurisdição e a duração razoável do processo.

Além disso, em caso de omissão na prestação da tutela jurisdicional pátria ou de morosidade infundada dos órgãos judiciais nacionais, haverá a violação do direito humano de acesso à justiça, autorizando o jurisdicionado, por meio de petições individuais, dirigir-se à Comissão Interamericana de Direitos Humanos a fim de apresentar denúncias ou queixas de violação a dispositivos da Convenção pelo Estado brasileiro, pois há mecanismos de monitoramento (arts. 44-51) garantidos no Pacto de San José que devem ser utilizados ${ }^{3}$ Logo, a Convenção Americana de Direitos Humanos evidencia que o acesso à justiça está dentre os direitos humanos, devendo ser efetivo, justo e em tempo razoável para a tutela jurisdicional de direitos de qualquer natureza, especialmente relacionados à saúde e à vida.

Dentro da sistemática de promoção do direito à saúde, novas tendências analíticas estão sendo utilizadas para equacionar os problemas enfrentados, uma delas é a utilização do chamado Direito Fraterno que, segundo Vial e Wünsch (2013, p. 4523-4524), considera o outro na condição de outro-eu, meu irmão, ou seja, alguém com quem faço pactos. Assim, tais pactos seriam acordos a serem feitos entre Estados, entre médico e paciente etc., conforme a necessidade a ser enfrentada.

No que tange a efetivação do direito à saúde, é preciso fazer pactos constantemente, pois envolvem questões orçamentárias e o próprio direito à vida que também é tutelado, não sendo por acaso que hoje se apregoa a necessidade de um 'Pacto pela Saúde', como compromisso público dos setores do SUS fundamentado nos princípios constitucionais, sendo imprescindível a efetivação também do 'Pacto pela Vida' em defesa do Sistema Único de Saúde e da gestão efetiva deste

3 Após o trâmite do processo perante a Comissão Interamericana de Direitos Humanos, se o Estado infrator não cumprir as diretrizes estabelecidas, o caso poderá ser encaminhado à jurisdição da Corte Interamericana de Direitos Humanos, pois somente os Estados Membros e a Comissão de Direitos Humanos podem submeter um caso à decisão da Corte, nos termos do art. 61 do Pacto de San José da Costa Rica. As pessoas individualmente dependem da Comissão de Interamericana de Direitos Humanos ou de outro Estado para que seus pleitos cheguem à apreciação da Corte. 
sistema (VIAL; WÜNSCH, 2013, p. 4523-4524).

\section{CONCLUSÃO}

A relação entre direito e saúde tem sido objeto de muitos estudos, sendo indispensável a verificação da influência dos regramentos internacionais para sua efetivação adequada, principalmente no contexto do subsistema interamericano de direitos humanos com vistas ao fortalecimento do Estado Democrático de Direito.

Quanto à promoção da saúde, trata-se, ao mesmo tempo, direito e dever fundamentais a serem garantidos pelo Estado através de políticas públicas adequadas e eficientes, sendo necessária a participação de particulares e da sociedade mediante pactos integrativos, consoante aponta a corrente defensora do Direito Fraterno.

No entanto, não há como discutir a efetivação dos direitos fundamentais, inclusive a saúde, sem o acesso à justiça que deve ser justo, efetivo e em tempo razoável no intuito de concretizar a justiça social. Na atualidade, é atributo do Poder Judiciário, através do exercício da jurisdição, a efetividade desses direitos, principalmente da saúde no intuito de buscar a resolução pacífica dos conflitos sociais.

Em alguns casos, há ausência total de acesso à tutela jurisdicional pelos cidadãos que se encontram marginalizados pelo capitalismo global ou, como na maioria dos casos, este acesso é precário em face de um Poder Judiciário lento, moroso e inefetivo socialmente na concretização de direitos, afrontando a dignidade humana, a duração razoável do processo, enfim, as garantias judiciais previstas na Constituição de 1988 e no Pacto de San José da Costa Rica.

Não se pode olvidar que o Pacto de San José da Costa Rica foi incorporado no ordenamento jurídico brasileiro com natureza de norma materialmente constitucional, indicando ao Estado que a prestação da tutela jurisdicional deve ser justa, efetiva e em tempo razoável, na condição de direito humano e fundamental no intuito de concretizar a justiça social, principalmente em relação ao basilar direito à saúde cuja judicialização vertiginosa após a Constituição de 1988 indica que a Administração Pública não está implementando adequadas políticas públicas nesta seara.

Em seu cinquentenário, a Convenção Americana de Direitos Humanos se mostra atualíssima, pois possui preceitos basilares para a garantia de acesso à justiça com efetividade e em tempo razoável (arts. $8^{\circ}$ e 25) dos cidadãos brasileiros s ser aplicados no Brasil que livremente aderiu a este tratado internacional, incorporado no ordenamento jurídico pátrio como norma materialmente constitucional. Em caso de omissão na prestação da tutela jurisdicional pátria ou de morosidade infundada dos órgãos judiciais nacionais, o jurisdicionado poderá encaminhar petições individuais à Comissão Interamericana de Direitos Humanos, denunciando a violação, pelo Estado brasileiro, do direito humano de acesso à justiça garantido no Pacto de San José, em especial para a prestação de tutela jurisdicional na seara da saúde.

Sendo o direito fundamental e social à saúde inerente à dignidade da pessoa humana, à sua integridade física e, sobretudo, à sua vida, é notório que o Pacto de San José da Costa Rica 
viabiliza a concretização judicial de políticas públicas de saúde, concretizando a justiça social nos casos apreciados pelos órgãos jurisdicionais. Portanto, em face da crescente judicialização de direitos vivenciada no Brasil nas últimas décadas, o acesso à tutela jurisdicional justa, efetiva e em tempo razoável para os cidadãos, em especial nos casos envolvendo a saúde, atendem as diretrizes do Direito Fraterno, da Constituição Cidadã e do Pacto San José da Costa Rica.

\section{REFERÊNCIAS}

ALEXY, Robert. Teoria dos direitos fundamentais. São Paulo: Malheiros, 2008.

ARISTÓTELES. Ética a nicômaco. Tradução de Pietro Nassetti. São Paulo: Martin Claret, 2006.

BARBOSA, Rui. Escritos e discursos seletivos. Rio de Janeiro: Nova Aguilar, 1997.

BARRETO JÚNIOR, Irineu Francisco; PAVANI, Miriam. O direito à saúde na Ordem Constitucional Brasileira. Revista Direitos e Garantias Fundamentais, Vitória, v. 14, n. 2, p. 71-100, jul./dez. 2013.

BERGEL, Jean-Louis. Teoria geral do direito. Tradução de Maria Ermantina de Almeida Prado Galvão. 2. ed. São Paulo: Martins Fontes, 2006.

BRASIL. [Constituição (1988)]. Constituição da República Federativa do Brasil de 1988. Brasília, DF: Presidência da República, 1988. Disponível em: http://www.planalto.gov.br/ ccivil_03/constituicao/constituicao.htm. Acesso em: 5 mar. 2020.

BRASIL. Lei n ${ }^{\mathbf{8 . 0 8 0}}$, de 19 de setembro de 1990. Dispõe sobre as condições para a promoção, proteção e recuperação da saúde, a organização e o funcionamento dos serviços correspondentes e dá outras providências. Brasília, DF: Presidência da República, 1990. Disponível em: http:// www.planalto.gov.br/ccivil_03/leis/18080.htm. Acesso em: 16 out. 2019.

BRASIL. Supremo Tribunal Federal. Suspensão de tutela antecipada no 175. Disponível em: http://portal.stf.jus.br/processos/detalhe.asp?incidente=2570693. Acesso em: 18 dez. 2019.

CERQUEIRA JÚNIOR, Carlos Alberto Cardoso; CAVALCANTI, Vanessa Ribeiro Simon. A judicialização do direito humano à saúde: uma discussão acerca da efetivação de direito essencial, por meio da prestação jurisdicional, sem prejuízos ao mínimo existencial. Revista Jurídica Portucalense, Porto, n. 20, 2016. doi: http://dx.doi.org/10.21788/issn.21835705(20)2016.ic-01.

COMPARATO, Fábio Konder. A afirmação histórica dos direitos humanos. São Paulo: Saraiva, 2007.

CUNHA, Rodrigo Giostri. O processo do trabalho como instrumento de efetivação dos direitos sociais trabalhistas: contribuições para o aprimoramento da prestação jurisdicional trabalhista. 2008. Dissertação (Mestrado) - Universidade de São Paulo, São Paulo, 2008.

DELGADO, Maurício Godinho. Princípios de direito individual e coletivo do trabalho. 2. ed. São Paulo: LTr, 2004. 
FIORATI, Jete Jane. A evolução jurisprudencial dos sistemas regionais internacionais de proteção aos direitos humanos. Revista dos Tribunais, São Paulo, v. 722, p. 10-24, dez. 1995.

IKAWA, Daniela Ribeiro; KWEITEL, Juana; MATTAR, Laura. O sistema interamericano de direitos humanos (introdução à parte VI. A). In: PIOVESAN, Flávia (coord.). Código de direito internacional dos direitos humanos anotado. São Paulo: DPJ Editora, 2008. p. 1135-1158.

LESSA, Luiz Carlos. Dicionário da doutrina social da igreja: doutrina social da igreja de A a Z. São Paulo: LTr, 2004.

MAGALHÃES, Breno Baía; FERREIRA, Vanessa Rocha. STF e os parâmetros para judicialização da saúde. Disponível em: https://www.jota.info/opiniao-e-analise/artigos/stf-eos-parametros-para-judicializacao-da-saude-16012017. Acesso em: 18 dez. 2019.

MARKY, Thomas. Curso elementar de direito romano. 10. ed. São Paulo: Saraiva, 2010.

NABAIS, José Casalta. Por uma liberdade com responsabilidade. Coimbra: Coimbra Editora, 2007.

NOVAES, Jorge Reis. Direitos fundamentais: trunfos contra a maioria. Coimbra: Coimbra Editora, 2004.

OEA. Convención americana sobre derechos humanos suscrita en la conferencia especializada interamericana sobre derechos humanos. Disponível em: http://www.oas.org/ es/sla/ddi/tratados_multilaterales_interamericanos.asp. Acesso em: 17 dez. 2019.

OMS - ORGANIZACIÓN MUNDIAL DE LA SALUD. Deteccion precoz del deterioro de la salud debido a la exposicion professional: informe de um grupo de estudo de la OMS. Ginebra: OMS, 1975.

PIOVESAN, Flávia. Direitos humanos e constitucionalismo regional transformador: o impacto do sistema interamericano. Revista Doutrinas Essenciais de Direito Constitucional, São Paulo, v. 8, p. 293-316, ago. 2015.

PIOVESAN, Flávia. Direitos humanos e o direito constitucional internacional. 7. ed. São Paulo: Saraiva, 2006.

RÁO, Vicente. O direito e a vida dos direitos. 6. ed. São Paulo: Revista dos Tribunais, 2005.

ROCHA, José Cláudio; ALVES, Cristiano Cruz. O acesso à justiça: ao Poder Judiciário ou à ordem jurídica justa? Revista Meritum, Belo Horizonte, v. 6, n. 1, p. 133-161, jan./jun. 2011.

ROSS, Alf . Direito e justiça. Tradução e notas de Edson Bini. Bauru, Edipro, 2008.

SARLET, Ingo Wolfgang; FIGUEIREDO, Mariana Filchtiner. Algumas considerações sobre o direito fundamental à proteção e promoção da saúde aos 20 anos da Constituição Federal de 1988. Revista Doutrinas Essenciais de Direitos Humanos, São Paulo, v. 3, p. 775-829, ago. 2011.

STARK, Christian Stark. Direitos sociais em tratados internacionais, constituições e leis. In: LEITE, George Salomão; SARLET, Ingo Wolfgang. Direitos fundamentais e Estado 
Constitucional: estudos em homenagem a J. J. Gomes Canotilho. São Paulo: Revista dos Tribunais, 2009.

STEINMETZ, Wilson. A vinculação dos particulares a direitos fundamentais. São Paulo: Malheiros, 2004.

SURYAN, Jaqueline. O direito à saúde no direito comparado: do Brasil ao mundo. Revista de Direito Constitucional e Internacional, São Paulo, v. 86, p. 39-72, jan./mar. 2014.

USP. Biblioteca virtual de direitos humanos. Universidade de São Paulo. Disponível em: http://www.direitoshumanos.usp.br. Acesso em: 18 dez. 2019.

VIAL, Sandra Regina Martini; WÜNSCH, Marina Sanches. Direito, saúde e o pressuposto da fraternidade na sociedade contemporânea. Revista do Instituto do Direito Brasileiro, São Paulo, ano 2, n. 5, p. 4517-4560, 2013.

VILLEY, Michel. O direito e os direito humanos. São Paulo: Martins Fontes, 2007.

Como citar MARTINS, Juliane Caravieri; AFONSO, Igor Vinícius de Lima. O direito e acesso à justiça efetiva e em tempo razoável e o pacto e san-josé da costa rica na proteção do direito à saúde. Scientia Iuris, Londrina, v. 24, n. 2, p.81-100, jul. 2020. DOI: 10.5433/2178-8189.2020v24n2p81. ISSN: 2178-8189.

Recebido em 19/02/2020

Arovado em: 09/04/2020 